\title{
RELATOS DE EXPERIÊNCIA

\section{Trajetória escolar de estudantes das classes populares e acesso ao ensino superior}

Regina Lúcia Cerqueira Dias ${ }^{\mathrm{I}, \mathrm{II}}$

http://dx.doi.org/10.24109/2176-6681.rbep.98i248.2679

\section{Resumo}

O artigo objetiva descrever e analisar as trajetórias escolares de estudantes das classes populares. Visa também compreender a importância da vivência desses sujeitos em um curso pré-universitário popular para o acesso ao ensino superior. A pesquisa realizada utilizou uma abordagem biográfica e foram reconstituídas e analisadas as trajetórias escolares e pessoais de dois indivíduos egressos do Curso Pré-Universitário Popular Práxis, pré-vestibular popular situado em Niterói, que obtiveram êxito em exames vestibulares e ingressaram no ensino superior. A análise das entrevistas feitas com os participantes da pesquisa mostrou que os itinerários escolares desses sujeitos foram extremamente acidentados e que houve uma mobilização intensa por parte deles e de seus familiares para prosseguirem em seus estudos. O Pré-Universitário Popular Práxis e outros pré-vestibulares frequentados pelos participantes mostraram-se fundamentais para que eles tivessem acesso ao ensino superior, pois os ajudaram a preencher lacunas em seus conhecimentos disciplinares e adquirir informações relevantes para alcançarem esse nível de ensino.

Palavras-chave: acesso ao ensino superior; estudantes das classes populares; pré-vestibulares populares.

Universidade Federal Fluminense (UFF), Niterói, Rio de Janeiro, Brasil. E-mail: <regcerdias@yahoo.com.br>; $<$ http://orcid.org/0000-00019530-6691>

II Doutora em Educação pela Universidade Federal de Minas Gerais (UFMG), Belo Horizonte, Minas Gerais, Brasil. 


\section{Abstract \\ School Trajectory of Students from Popular Classes and the Access to Higher Education}

This article aims to describe and analyse the school trajectories of students from popular classes. It also aims to understand the importance of the experiences of these subjects in a popular pre-university course for access to higher education. The research used a biographical approach and it were reconstructed and analysed the educational and personal trajectories of two individuals egress from the popular pre-university course Praxis, located in Niterói, whom were successful in entrance exams and had entered to higher education. The analysis of the interviews into the research's participants showed that the school trajectories of these subjects had been extremely bumpy and that there had been an intense mobilization by them and their relatives to continue to study. The popular pre-university course Praxis and other pre-university courses frequented by research's participants had been essential for them for access to higher education because they helped them to fill gaps in their curricular knowledge and acquire important information to achieve this level of education.

Keywords: access to higher education; students of popular classes; popular pre-university courses.

\section{Introdução}

Este artigo tem como objetivo central descrever e analisar as trajetórias escolares de estudantes das classes populares. Objetiva também compreender a importância da vivência desses sujeitos em um curso pré-universitário popular para o acesso ao ensino superior.

O interesse em investigar tais questões adveio da minha atuação em um pré-vestibular popular, denominado Pré-Universitário Popular Práxis, que é um projeto de extensão da Faculdade de Educação da Universidade Federal Fluminense (FEUFF) criado em 2008. Leciono a disciplina Sociologia da Educação na referida instituição e faço parte de um grupo de pesquisa que tem como propósito investigar questões relacionadas ao acesso e à permanência no ensino superior.

Em virtude dessas experiências, foi definido o objeto deste estudo e realizada uma pesquisa em que se procurou descrever e analisar a trajetória escolar e pessoal vivida por dois indivíduos oriundos das classes populares, egressos do Curso Pré-Universitário Popular Práxis, que obtiveram êxito em exames vestibulares e ingressaram no ensino superior.

Considerando as características específicas do objeto de estudo, optamos por realizar uma pesquisa qualitativa, utilizando a abordagem biográfica. Procuramos, ao usar tal abordagem metodológica, reconstruir 
as histórias de vida narradas pelos participantes da pesquisa nas entrevistas, que foram semiestruturadas e em profundidade. ${ }^{1}$

Tem sido objeto de pesquisa no campo educacional o sucesso escolar dos alunos oriundos das camadas populares. Os trabalhos nessa área, tanto internacional (Lahire, 1997; Laurens,1992) como nacionalmente (Portes, 2001; Silva, 2011; Viana, 2007; Zago, 2000), buscam identificar fatores que explicariam o prosseguimento nos estudos por esses alunos. Dessa forma, os trabalhos realizados por tais autores, especialmente a investigação efetivada por Lahire (1997), foram fundamentais para que pudéssemos descrever e analisar os itinerários escolares e o acesso dos participantes da pesquisa ao ensino superior.

Os dois sujeitos da pesquisa, um do sexo feminino e outro do sexo masculino, são negros e, apesar dos inúmeros desafios enfrentados em virtude do pertencimento étnico-racial e de classe, conseguiram ingressar no ensino superior. A estudante entrevistada, Paula, ${ }^{2}$ conseguiu, em 2013, ser aprovada no vestibular promovido pela Universidade Estadual do Rio de Janeiro (UERJ), no campus situado no município de São Gonçalo - cidade localizada próxima à capital -, e passou a cursar História na instituição. O outro participante, Carlos, logrou aprovação em Direito, curso considerado de prestígio, entre outros motivos, devido à grande procura de candidatos, que excede muito o número de vagas disponíveis, na mesma instituição em que Paula cursa História. A escolha dos dois se deu pela indicação dos coordenadores pedagógicos do Pré-Universitário Práxis, aos quais solicitei que apontassem dois ex-alunos que tivessem sido aprovados em vestibulares promovidos por instituições de ensino superior ou no Exame Nacional do Ensino Médio (Enem) e ingressado no ensino superior. Pedi também aos coordenadores que um dos ex-alunos indicados tivesse sido aprovado em cursos de maior prestígio social, como Direito, Medicina e Engenharia. ${ }^{3}$

Esta investigação está baseada na teoria da ação que sustenta as obras produzidas por Pierre Bourdieu e Bernard Lahire, autores importantes para a compreensão do processo de escolarização das classes populares, e em estudos desenvolvidos por autores que realizaram pesquisas sobre os prévestibulares populares, como Zago (2008), Nascimento (2012), Whitaker (2010) e Carvalho (2006). A vivência dos entrevistados no Pré-Vestibular Práxis e em outros pré-vestibulares populares que será descrita e analisada posteriormente se mostrou fundamental para o acesso de Paula e Carlos ao ensino superior.

\section{Configurações familiares e trajetórias escolares dos participantes da pesquisa no período anterior ao ingresso no Pré-Universitário Popular Práxis}

\section{Paula}

Paula nasceu no ano de 1964, em Jacuípe, um vilarejo situado no estado da Bahia. Seus pais, trabalhadores rurais, criaram com muita dificuldade os cinco filhos, quatro mulheres e um homem. A entrevistada é a segunda

\footnotetext{
As entrevistas "em profundidade" são aquelas que apresentam maior flexibilidade, permitindo ao entrevistado construir suas respostas sem ficar preso a um nível mais rigoroso de diretividade e mediação por parte do entrevistador, como acontece no caso de uso de questionário ou de entrevista totalmente estruturada (Oliveira; Martins; Vasconcelos, 2012).

2 Paula e Carlos são nomes fictícios atribuídos pela pesquisadora aos participantes do estudo.

3 Vargas (2008) afirma, com base nos dados extraídos do Exame Nacional de Desempenho dos Estudantes (Enade), que, mesmo em momento de grande expansão, o ingresso de estudantes pertencentes às classes populares ao ensino superior se deu de maneira segmentada, pois tais estudantes são subrepresentados em cursos de maior prestígio social, como Direito, Medicina e Engenharia.
} 
filha mais velha. Sua mãe é analfabeta e seu pai, já falecido, frequentou por poucos anos a escola, mas sabia ler e escrever. Sobre a escolaridade de seus avós paternos e maternos, a entrevistada disse que possuía poucas informações e não soube falar acerca do assunto.

Lahire (1997) explicita, em seu estudo, cinco temas fundamentais para análise da relação família-escola no que se refere aos resultados escolares de crianças provenientes desses meios: as formas familiares da cultura escrita; as condições e disposições econômicas; a ordem moral doméstica; as formas de autoridade familiar; e as formas familiares de investimento pedagógico. Uma das conclusões a que chega o autor, acerca dos casos de sucesso escolar de crianças dos meios populares, está relacionada à consonância existente entre as configurações familiares e a escola. Mesmo em famílias que possuíam capital econômico, cultural, social e escolar reduzidos, ou mesmo na ausência de capital escolar - casos de pais analfabetos -, algumas crianças estavam em situação de sucesso porque as configurações dessas famílias engendravam um perfil de estudante que é esperado pelas escolas primárias. Os professores tendem a almejar um estudante participativo que, entre outras coisas, obedeça as regras, cumpra bem seus deveres e reconheça a autoridade do professor e a importância da instituição escolar para um futuro exitoso. No entanto, o autor observou, nos casos de consonância entre escola e família, uma tendência ao sucesso escolar e não um processo inexorável. Na entrevista realizada com a participante da pesquisa, procurei, inicialmente, retratar a configuração familiar de origem. Dessa forma, solicitei a Paula e também a Carlos que falassem sobre seus pais, irmãos e avós e sobre a dinâmica familiar, tendo como base os cinco temas elencados por Lahire em seu estudo.

Segundo Paula, ela e seus irmãos foram educados seguindo regras e sob a égide disciplinadora do pai, que era bastante rigoroso com os filhos. A mãe também exercia sua autoridade, mas de acordo com a entrevistada, de maneira bem diversa do marido, pois era calma e conversava com os filhos, estabelecendo regras e limites de forma suave. Os pais de Paula trabalharam muitos anos como "boias-frias" em plantações de cana, em um tipo de atividade extremamente cansativa e mal paga. Posteriormente, sua mãe conseguiu emprego como gari na prefeitura do município. Seus pais, portanto, tiveram uma vida profissional marcada pela luta intensa e, ainda assim, não abdicaram da educação dos filhos. Havia na casa dela uma regularidade em relação às atividades, horários e regras que, de acordo com Lahire (1997, p. 26), "produzem estruturas cognitivas ordenadas, capazes de pôr ordem, gerir, organizar os pensamentos", ou seja, propiciam uma ordem cognitiva que é esperada pelas escolas primárias. Dessa maneira, tal configuração familiar compensou, de certo modo, o reduzido capital escolar e econômico que os pais de Paula possuíam.

Paula relatou que sua mãe desejava que os filhos estudassem e dizia sempre a seguinte frase: "eu sou analfabeta, então não quero isso para vocês, todos têm que ir para a escola". E para que tal desejo se tornasse realidade, a mãe destinava parte do dinheiro que recebia como trabalhadora braçal para comprar livros e uniformes para os filhos. Esse investimento 
dos pais, especialmente das mães, na educação dos filhos coincide com os achados de pesquisas efetivadas por Lahire (1997), Portes (2001), Zago (2000) e outros que investigam o sucesso escolar de estudantes pertencentes aos meios populares. O estudo realizado por Lahire (1997) sobre a escolarização de crianças das classes populares é importante, entre outros motivos, porque nos mostra que a omissão parental é um mito várias vezes utilizado pelos professores para justificarem o fracasso escolar de crianças pertencentes a esses meios.

Paula iniciou seus estudos em uma escola particular, onde foi alfabetizada aos 7 anos de idade, pois não conseguiu vaga em uma instituição pública. Como a mensalidade era bastante cara para seus pais, a proprietária e diretora da escola permitiu que eles pagassem uma quantia menor para que ela pudesse estudar. Posteriormente, Paula continuou seus estudos em uma escola pública do município.

Perguntei à entrevistada se havia alguém para ajudá-la nos deveres de casa e que pudesse sanar suas dúvidas sobre as disciplinas ensinadas. Ela disse que estudava sozinha, pois seus pais não dispunham de tempo e, ademais, sua mãe, analfabeta, não possuía capital escolar para auxiliá-la. Seus irmãos também não cumpriram tal papel. A estratégia utilizada por Paula, em toda a sua escolarização, foi recorrer aos professores quando tinha dúvidas. Ela relatou que era uma aluna participativa e fazia muitas perguntas sobre os conteúdos disciplinares estudados, especialmente Matemática, disciplina na qual apresentava bastante dificuldade.

Lahire (1997) comenta sobre a solidão dos alunos das classes populares, que costumam experimentar esse sentimento por estarem distantes do universo escolar, devido especialmente ao reduzido capital cultural de suas famílias. Tal solidão persiste quando voltam da escola para casa, pois não podem, muitas vezes, contar com a ajuda de seus pais no que diz respeito às dúvidas que possuem sobre os conteúdos escolares. Portanto, a maneira de ser de Paula como aluna, sua desinibição diante dos professores, aos quais sempre recorria para sanar seus questionamentos, foi essencial para o prosseguimento nos estudos, amenizando ainda o sentimento de solidão explicitado pelo autor.

Na casa de Paula, só havia livros didáticos, pois seus pais não possuíam recursos para comprar livros de literatura, dicionários, enciclopédias etc. Devido a esse fato, durante muitos anos, não foi possível a ela desfrutar, em casa, da leitura de outros tipos de livros. Indaguei a Paula se sua mãe contava histórias para ela, já que, como era analfabeta, não poderia ler. A entrevistada respondeu que ela não as contava, pois com a longa jornada de trabalho fora de casa, somada aos trabalhos domésticos, não havia tempo. O pai de Paula também não lia ou contava histórias para ela. Apesar de não poderem auxiliar nas tarefas trazidas da escola, ler para ela ou mesmo contar histórias, seus pais, especialmente a mãe, contribuíram para sua longevidade escolar, ao manterem um discurso favorável à escolarização dos filhos, no caso da mãe, e colocarem em prática uma ordem moral doméstica que favorecia a adequação à escola. 
4 Em relação ao campo de produção simbólica, Bourdieu (2003) analisa a imposição da cultura dominante aos dominados, os quais a veem como a cultura legítima, como se esta estivesse fundamentada em uma verdade objetiva. $\mathrm{Na}$ perspectiva de Bourdieu, uma cultura não pode ser objetivamente definida como superior a outra, mas, em uma sociedade de classes, os valores arbitrários capazes de se impor como cultura legítima seriam aqueles sustentados pelas classes dominantes (Nogueira; Nogueira, 2004, p. 84-85).
A instituição de ensino frequentada por Paula em Jacuípe até os 18 anos, quando se mudou para o estado do Rio de Janeiro, era, segundo ela, uma boa escola, levando-se em consideração que estava localizada em uma cidade do interior da Bahia. Relatou que a escola era dirigida por um professor que exercia uma liderança positiva, além de contar com bons professores.

Durante esses anos, Paula só trabalhava no período das férias escolares, quando ia para a roça junto a sua mãe. O dinheiro que recebia pelo trabalho nas plantações de cana era utilizado para comprar roupas para ela e uma irmã. Ou seja, mesmo enfrentando inúmeras dificuldades financeiras, seus pais não permitiam que os filhos trabalhassem no período escolar, a fim de que pudessem se dedicar integralmente aos estudos.

Essa escola em Jacuípe não oferecia aos alunos vivências culturais consideradas legítimas ${ }^{4}$ e diferentes daquelas existentes em seu meio cultural. No vilarejo em que morou até os 18 anos, não havia cinema nem teatro e, portanto, Paula só assistiu a um filme em uma sala de cinema quando se mudou para o estado do Rio de Janeiro. Aos 18 anos, conforme mencionado anteriormente, Paula se mudou para o Rio de Janeiro e passou a residir em São Gonçalo, cidade localizada próxima à capital. Ela relatou que desejava, com essa mudança, principalmente, estudar, mas também "conquistar alguma coisa na vida", o que seria impossível se permanecesse em Jacuípe, pois as oportunidades de conseguir um bom emprego eram pequenas e ela não poderia ter acesso ao ensino superior, por não haver instituições que ofertassem esse nível de ensino no município. Percebe-se, pela narrativa da entrevistada, o firme desejo de estudar, o qual nunca abandonou. Mesmo sendo oriunda de uma família desfavorecida socialmente e culturalmente, não interiorizou a ideia de que o ensino superior não seria possível para ela, algo que tende a ocorrer comumente, de acordo com Bourdieu (1998), com indivíduos pertencentes às classes populares que aprendem a sonhar com o possível às condições objetivas de vida que possuem.

Paula, então, passou a morar com uma tia, em São Gonçalo, e logo ao chegar se matriculou em uma escola municipal de Niterói, cidade próxima ao município em que residia. A entrevistada foi reprovada duas vezes durante a sua escolarização, na $7^{\mathrm{a}}$ série (atualmente denominada $8^{\circ}$ ano) e no $1^{\circ}$ ano do ensino médio, quando já estudava em Niterói. Tais reprovações não a fizeram desistir do sonho de continuar sua escolarização e ter acesso ao ensino superior. Paula passou a trabalhar como faxineira para sobreviver e continuar estudando. Quando finalizou o ensino médio, fez vestibular para o curso de Administração na UFF e não foi aprovada. Para aumentar sua decepção com a reprovação, tirou zero em três disciplinas. Paula talvez tenha percebido nesse momento a fragilidade dos conhecimentos disciplinares adquiridos durante seu processo de escolarização e, por alguns anos, o desânimo tomou conta de seu espírito. Além de não tentar novamente aprovação em vestibulares promovidos pelas instituições de ensino por alguns anos, Paula engravidou, casou-se e teve um filho, aos 24 anos de idade. Quando seu filho estava com quatro anos, ela separou-se de seu marido. Trabalhava no Rio de Janeiro fazendo faxinas e ainda cuidava do seu filho, contando com a ajuda valiosa de uma vizinha. 
Quando seu filho completou 21 anos, Paula resolveu investir novamente em seu desejo de entrar na universidade e matriculou-se em um curso pré-vestibular popular. Bourdieu (1998) afirma que as informações sobre os sistemas de ensino fazem parte do capital cultural, e, normalmente, as classes populares não possuem tais informações, que são fundamentais para que o indivíduo possa investir seus capitais em instituições de ensino, em cursos rentáveis e de prestígio, e consiga também prosseguir seus estudos. A entrevistada relatou que a falta de informações sobre o que fazer para continuar seus estudos, sobre a existência de pré-vestibulares populares, foi o principal motivo de ter conseguido acesso ao ensino superior somente muitos anos depois de sua chegada ao estado do Rio de Janeiro.

\section{Carlos}

Carlos nasceu na cidade do Rio de Janeiro em 1981. Oriundo de uma família pertencente às classes populares, sua mãe teve cinco filhos, duas mulheres e três homens, um deles falecido. A mãe de Carlos casou-se duas vezes. O entrevistado é o segundo filho mais velho. Sua mãe trabalhou por toda a vida como empregada doméstica. Quando Carlos estava com um ano de idade, seus pais se separaram. O entrevistado disse que tem poucas informações sobre seu pai, pois não manteve mais contato com ele após essa separação.

A mãe de Carlos nasceu no Maranhão e migrou para o estado do Rio de Janeiro em busca de emprego e uma vida melhor. De acordo com o participante, sua mãe estudou até a antiga $4^{\text {a }}$ série do primário (hoje denominada $5^{\circ}$ ano do ensino fundamental) e é analfabeta funcional. Seus avós maternos e a maior parte dos tios são analfabetos. A avó materna teve 12 filhos e todos trabalhavam no campo. Pertencente a uma família numerosa e com parcos recursos financeiros, a mãe de Carlos foi obrigada a trabalhar muito cedo e não teve oportunidade de continuar sua escolarização. Sobre a escolaridade dos avós paternos Carlos não tem informações.

Quando Carlos tinha um ano de idade, foi morar com a avó materna no Maranhão. A mãe dele havia se separado de seu pai e não tinha no momento condições financeiras para criar os dois filhos. De acordo com o entrevistado, ela precisava de um tempo para estabilizar-se financeiramente. Dessa forma, ele passou a viver com sua avó e só voltou ao Rio de Janeiro, e passou a morar novamente com sua mãe, aos nove anos de idade.

A avó de Carlos morava em um sítio próximo a São Luis, capital do Maranhão, e era lavradora. Ele tem boas recordações de sua avó e a descreve como uma pessoa fantástica. Durante os anos passados no Maranhão, ele não frequentou uma escola; no entanto, foi alfabetizado em casa. Carlos acredita que foi alfabetizado por uma tia, mas não soube informar com precisão. Em 1990, ele e sua irmã passaram novamente a viver com a mãe, em São Gonçalo, município situado no Rio de Janeiro e próximo à capital. O entrevistado relatou que nessa época sua mãe já havia 
se estabilizado financeiramente e poderia cuidar novamente dos filhos. Com 10 anos, ingressou pela primeira vez em uma escola, localizada em Niterói. Segundo ele, sua mãe sempre dizia que não foi possível a ela continuar a estudar, mas que julgava absurdo as pessoas que têm oportunidade de fazê-lo muitas vezes não quererem.

Carlos relatou que fazia os seus deveres sozinho. Sua mãe trabalhava muito e, por ter estudado pouco, não conseguia ajudá-lo nas tarefas que trazia para casa. Seu padrasto possuía uma maior escolarização, comparada, principalmente, aos outros parentes. Ele chegou a completar o ensino médio e trabalhou em supermercados e faculdades, nessas últimas, como inspetor. No entanto, a relação de Carlos com seu padrasto era péssima e, desse modo, o entrevistado não se beneficiou de sua ajuda em seu processo de escolarização. Ou seja, como aponta Lahire (1997), não adianta ter pais ou avós que possuam capitais cultural e escolar, se eles não estão próximos das crianças em seu cotidiano ou não dispõem de tempo, ou mesmo de interesse em oferecer tais capitais para o desenvolvimento cognitivo dessas crianças.

Indaguei a Carlos sobre as estratégias que ele utilizou para superar a solidão que sentiu durante sua escolarização, sentimento esse também experimentado por Paula e que, conforme dito anteriormente, tende a ser comum aos indivíduos pertencentes às classes populares. Carlos disse que sempre foi autodidata e visto como um ótimo aluno pelos professores. Estudava muito, inclusive, antecipando as matérias que ainda seriam ensinadas pelos docentes. Como sua mãe trabalhava bastante, até mesmo nos fins de semana em alguns períodos, ele relatou que desde muito cedo aprendeu a resolver seus problemas sem ajuda da família.

Além da imensa força de vontade de Carlos, sua grande iniciativa diante dos problemas e seu autodidatismo - características evidenciadas em sua narrativa -, foi possível também identificar como fator favorável para sua longevidade escolar a ajuda recebida de alguns professores em seu processo de escolarização e em sua vida pessoal. Carlos relatou que tinha o hábito de conversar bastante com os professores. Além de pedir o auxílio deles para solucionar suas dúvidas sobre os conteúdos disciplinares, conversava sobre outros assuntos que não diziam respeito estritamente à escola.

Havia também, na casa de Carlos, regras e horários que eram estabelecidos por sua mãe e seu padrasto para que conseguissem dar ordem ao cotidiano familiar. Ele disse que morava em um bairro bastante perigoso, onde havia tráfico de drogas. Dessa forma, sua mãe não permitia que os filhos ficassem na rua até tarde. Silva (2011), no estudo que desenvolveu, também observou tal estratégia utilizada por parte de algumas famílias das classes populares em relação à criação dos filhos. Portanto, a mãe e o padrasto, ainda que possuíssem um reduzido capital econômico e cultural, exerceram autoridade sobre os filhos e buscaram construir um ambiente familiar ordenado para eles.

Depois de cursar a primeira e a segunda série do ensino fundamental em uma escola de Niterói, Carlos ficou dois anos sem estudar. A mãe tirou-o da escola porque desejava levá-lo para estudar em regime de internato em 
uma escola situada no Rio de Janeiro. A informação sobre tal instituição de ensino foi dada à mãe do entrevistado por sua patroa. No entanto, esse desejo de Carlos e de sua mãe não se concretizou, depois de tentar por dois anos o ingresso do filho nessa escola. O entrevistado relatou o desespero que sentiu ao ficar em casa por esse período longe da escola. Perguntei o que fez durante esse tempo e ele respondeu que lia bastante e estudava sozinho. Como sua mãe contava para as pessoas que o filho mais velho gostava muito de ler, elas davam diversos livros para ele. Carlos buscou sozinho informações sobre alguma escola onde pudesse retomar seus estudos e sua mãe acabou por matriculá-lo em um Centro Integral de Educação Pública (Ciep). ${ }^{5}$

Percebemos com a narrativa tecida que houve "o encontro entre o juízo corrente na família e o vinculado por profissionais da unidade escolar" (Silva, 2011). O entrevistado era visto pelos professores como um bom aluno e sua mãe também acreditava em sua capacidade intelectual, o que acabou por favorecer a permanência na instituição escolar, ainda que tal itinerário tenha sido acidentado, com interrupções ao longo do percurso.

Assim como Zago (2000) e Viana (2007), que pesquisaram sobre a longevidade escolar de indivíduos pertencentes aos meios populares, pude perceber, em análise que desenvolvi (Dias, 2010), como os itinerários escolares desses indivíduos costumam ser extremamente acidentados. Além disso, o estudo costuma ocorrer concomitantemente ao trabalho, como afirma Zago (2000), o que muitas vezes dificulta a caminhada, pois sobra um tempo menor para que o estudante se dedique à escola, somado ainda ao cansaço que o acúmulo de atividades gera. Nas histórias narradas por Carlos e por Paula, esse tipo de itinerário também foi evidenciado.

Carlos, portanto, passou a estudar em um Ciep. Ele fazia os deveres solicitados pelos professores na escola, jogava futebol à tarde, e ainda podia tomar o café da manhã, almoçar e lanchar na instituição. No entanto, ele relata que os Cieps nessa época já passavam por um processo de decadência.

Indaguei ao participante quando ele começou a trabalhar. Ele contou que durante a infância somente se dedicou aos estudos, exceto quando morou com sua avó materna e teve que trabalhar em uma pedreira. Durante sua adolescência, no entanto, ele estudou e trabalhou concomitantemente: acompanhava um rapaz que morava no bairro e vendia lanches na porta de casas onde aconteciam shows de música. O dinheiro que recebia entregava à mãe para ajudar nas despesas da casa.

De acordo com o entrevistado, quando tinha 14 anos de idade voltou a estudar na escola em que havia iniciado seus estudos em Niterói para fazer supletivo, pois estava um pouco atrasado em sua escolarização, devido à interrupção nesse processo. Ele soube que nesse colégio havia supletivo e mais uma vez demonstrou ter uma grande iniciativa para resolver os problemas que surgiam em sua vida. Como sua mãe trabalhava muito e não podia ir com ele fazer sua matrícula, ele teve de pensar em uma maneira de ingressar nessa instituição. Então, pediu a uma senhora que estava na fila para que assinasse o protocolo de matrícula para ele.

\footnotetext{
Os Cieps, de acordo com Menezes (2001), foram criados na década de 80 por Darcy Ribeiro, quando era Secretário da Educação no Rio de Janeiro, no governo de Leonel Brizola. O objetivo era proporcionar e duc a çã o, es portes, assistência médica, alimentos e atividades culturais variadas, em instituições colocadas fora da rede educacional regular.
} 
Carlos estudou por dois anos nessa escola, fez o supletivo e, posteriormente, cursou o ensino médio em outra instituição também situada em Niterói.

\section{O ingresso de Paula e Carlos no Pré-Vestibular Popular Práxis e o acesso ao ensino superior}

$\mathrm{O}$ acesso ao ensino superior por indivíduos pertencentes às classes populares foi por muito tempo, na história do Brasil, sistematicamente negado. Mesmo a elite brasileira era obrigada a ir para outros países, se quisesse ingressar nesse nível de ensino, uma vez que, durante três séculos, quando houve a dominação portuguesa sobre o Brasil, não havia faculdades e universidades. Somente a partir da vinda da corte portuguesa para o País, em 1808, foram criados os primeiros cursos superiores (não teológicos) na Colônia (Romanelli, 2007). Segundo Romanelli (2007, p. 38), Portugal tinha como propósito exclusivo "proporcionar educação para uma elite aristocrática e nobre de que se compunha a Corte".

A independência política do Brasil, conquistada em 1822, não modificou, pelo menos de imediato, o quadro da situação do ensino. O poder foi entregue, segundo a autora, para a elite brasileira, formada por proprietários de terras e de engenhos e letrados. E as novas faculdades criadas na década de 20, como as Faculdades de Direito, ainda que já existissem os cursos de Medicina, Engenharia e Artes, que as antecederam, assumiram o papel de formar os quadros superiores do Império, que comporiam o quadro geral da administração e da política.

No entanto, Portes (2001) afirma que a ausência de estudantes pobres e negros no ensino superior brasileiro não foi completa. Segundo o autor, a presença desses estudantes no ensino superior "data desde a criação dos cursos jurídicos em 1827 e se acentua com a instituição e a ampliação do aparato desse nível de ensino no século 20" (p. 520). Ainda que o acesso de estudantes dos meios populares ao ensino superior tenha se dado ao longo da história do Brasil, mesmo representando uma minoria nessa etapa de ensino, Portes (2011 p. 520) ressalta que "a permanência desse tipo de estudante, por outro lado, tem-se dado à revelia do Estado". De acordo com o autor,

\footnotetext{
para permanecer no sistema superior de ensino público de qualidade, o estudante pobre desenvolve um conjunto significativo de estratégias, pessoais e coletivas, materiais e simbólicas, pois ele não tem visibilidade no interior dos cursos e é visto na figura de um acadêmico universal (Portes, 2011, p. 520).
}

Nos últimos 13 anos, houve a ampliação de vagas no ensino superior, o que possibilitou um maior acesso das classes populares a esse nível de ensino. Tal ampliação e democratização ocorreu principalmente durante o governo do presidente Luís Inácio Lula da Silva, com a criação de políticas e a implementação de programas, como o Programa Universidade 
para Todos (ProUni) e o Programa de Apoio a Planos de Reestruturação e Expansão das Universidades Federais (Reuni). ${ }^{6}$

Ocorreu também, nas últimas décadas, a implementação de ações afirmativas que tornaram o acesso às instituições de ensino superior mais democrático. De acordo com Oliven (2007, p. 30), as ações afirmativas referem-se a:

um conjunto de políticas públicas para proteger minorias e grupos que, em uma determinada sociedade, tenham sido discriminados no passado. A ação afirmativa visa remover barreiras, formais e informais, que impeçam o acesso de certos grupos ao mercado de trabalho, universidades e posições de liderança.

A Lei de Cotas, sancionada em agosto de 2012, que determina a reserva de 50\% das vagas das instituições federais de ensino superior para estudantes das escolas públicas, considerando o critério raça/cor, é o resultado de uma luta intensa dos movimentos sociais pela igualdade de direitos e oportunidades.

De acordo com Nascimento (2012), os cursos pré-vestibulares populares que se originaram de iniciativas de professores e estudantes, na década de 90 do século 20, no Brasil, constituem-se em um movimento social e popular. Zago (2008, p. 151) afirma que tais cursos têm seu início em um contexto contraditório do sistema educacional: "se por um lado ampliou consideravelmente o número de vagas, de outro mantém profundas desigualdades no acesso ao ensino superior". Segundo a autora, não há como apresentar um número exato de pré-vestibulares existentes, mas as estimativas, de acordo com dados de 2001, apontam 800 núcleos no Brasil, sendo a maioria na região Sudeste. Outra característica desses cursos, explicitada por Zago (2008), com base na análise de estudos sobre os pré-vestibulares populares, é a gratuidade da maioria deles.

Tais cursos, de acordo com Nascimento (2012), têm como finalidade básica preparar os estudantes pertencentes às classes desfavorecidas socialmente para obterem êxito nos exames vestibulares de instituições de ensino superior. Empreender tal ação, que busca permitir o acesso ao ensino superior a grupos sistematicamente excluídos desse nível educacional, é, sem dúvida, de grande importância; mas Nascimento (2012, p. 21) ressalta que o referido movimento conseguiu ir além e advoga a tese de que

os questionamentos apresentados pelo Movimento dos Cursos Pré-Vestibulares às instituições de ensino superior em particular e às políticas educacionais em geral produziram demandas e propostas de democratização do direito ao ensino superior e, pois, de democratização das próprias instituições de ensino.

Portanto, tal movimento social colabora para a discussão e adoção pela sociedade brasileira das políticas de ação afirmativa, que, conforme já dito neste artigo, visam ao acesso de negros e pobres à educação superior.

\footnotetext{
6 O ProUni tem como objetivo a concessão de bolsas de estudos integrais e parciais a estudantes de baixa renda, em cursos de graduação e sequenciais de formação específica, em instituições filantrópicas e privadas de educação superior. O Reuni é um programa de expansão da rede federal. Foram criadas 14 novas universidades que possibilitaram a ampliação de vagas e a instituição de novos cursos de graduação.
} 
O Pré-Universitário Popular Práxis, cujas contribuições para a longevidade escolar de Paula e Carlos foram investigadas nesta pesquisa, é, atualmente, um projeto de extensão da Universidade Federal Fluminense. Teve seu início em 1999, no entanto, não surgiu como um projeto de extensão, mas como um projeto de ensino, criado pelo professor da instituição Jairo Paes Selles.

Após algumas mudanças em sua dinâmica, em 2003, o referido projeto de ensino tornou-se um projeto de extensão da UFF e, em 2008, passou a se chamar Pré-Universitário Popular Práxis. O Pré-Universitário Popular, desde a sua origem, quando ainda era um projeto de ensino, foi responsável por aprovações de diversos indivíduos pertencentes às classes desfavorecidas socialmente em vestibulares de instituições de ensino superior e, mais recentemente, no Enem. No entanto, não é possível saber o número exato de aprovados ao longo da história, pois somente nos últimos anos os coordenadores pedagógicos vêm sistematizando esses dados. ${ }^{7}$

O Práxis está localizado no campus do Valonguinho, região central de Niterói, e oferta, anualmente, 60 vagas para indivíduos que tenham cursado e concluído o ensino médio (ou estejam cursando o último ano) em escolas públicas. Caso o candidato queira ingressar no curso e tenha concluído o ensino médio em uma escola da rede privada, ou esteja no último ano desse nível, poderá participar do processo seletivo desde que tenha recebido ou receba bolsa de estudo. Outro critério para entrar no curso é que a renda total da família dividida pelo número de moradores seja igual ou inferior a $\mathrm{R} \$ 1.000,00$. O candidato não poderá estar cursando universidade pública ou privada. É solicitada ao aluno uma pequena quantia para custear os materiais didáticos, mas o pagamento não é obrigatório.

Diversos alunos egressos do Práxis que tiveram êxito nos vestibulares e no Enem e são universitários ou que já concluíram suas graduações tornaram-se colaboradores voluntários desse pré-universitário, lecionando ou atuando como coordenadores pedagógicos do projeto, como é o caso de Carlos, participante da pesquisa, que atualmente compõe a equipe de coordenadores. Como o Práxis é um projeto de extensão da FEUFF, portanto, vinculado à universidade, conta em sua equipe com estudantes da instituição que recebem bolsas, como a de extensão e de desenvolvimento acadêmico, e prestam uma ajuda valiosa aos coordenadores pedagógicos e professores que são voluntários. Apesar do auxílio institucional, a luta para manter o projeto funcionando é contínua e demanda um maior investimento no curso. Faltam recursos para melhorar a infraestrutura do projeto, salas de aula necessárias para a expansão etc.

Em 2016, 11 estudantes do Práxis foram aprovados em exames vestibulares promovidos por instituições de ensino superior e no Enem. Dez desses estudantes foram aprovados para ingressarem em curso de instituições de ensino superior públicas, como UFF, UERJ e UFRJ, e um deles para uma instituição de ensino superior particular.

Ainda que o principal objetivo do Práxis seja possibilitar a indivíduos de baixa renda a vivência em um curso de preparação para os exames de acesso ao ensino superior, a fim de que tenham ampliadas suas chances de êxito, sua proposta vai além. O Pré-Universitário Popular Práxis pretende também estimular a construção da consciência crítica e o crescimento dos alunos como cidadãos, promover o acesso aos códigos culturais e a ambientação com a realidade universitária. Possibilita ainda a formação dos alunos-mestres, ou seja, estudantes de licenciaturas que lecionam 
no curso e desenvolvem, na prática cotidiana, diversas habilidades e saberes inerentes à profissão docente.

Carvalho (2006), que desenvolveu um estudo sobre os cursos prévestibulares comunitários (CPVCs), ressalta que tais cursos enfrentam o dilema de serem "simultaneamente movimentos sociopolíticos de empoderamento, diversidade cultural e cidadania ativa, e instituições paraescolares lutando por ações inclusivas no ensino superior". No Pré-Universitário Popular Práxis, esse dilema é enfrentado pela equipe formada por coordenadores e professores em seu cotidiano. Os professores do Práxis ensinam os conteúdos que fazem parte dos exames vestibulares e do Enem, mas existem também as chamadas aulas temáticas. Nessas aulas, planejadas pelos coordenadores pedagógicos e pelos professores, questões e temas importantes para o desenvolvimento do senso crítico dos alunos e para a formação cidadã são discutidos, como o movimento feminista, o acesso e a permanência dos indivíduos das classes populares no ensino superior brasileiro etc.

Witaker (2010) afirma, diante do fato de que a participação dos jovens dos meios populares nos cursinhos populares consiste na adesão a uma estratégia utilizada pelos jovens das classes médias e elites, que "quando os pobres se apropriam de práticas da classe dominante, eles precisam reelaborá-las para torná-las funcionais às novas circunstâncias", o que, de acordo com ela, já está acontecendo nesses cursinhos. É possível perceber, nas aulas temáticas desenvolvidas pelos professores e coordenadores do Práxis, um exemplo da reelaboração defendida pela autora.

Vários alunos do Práxis chegam ao pré-universitário com uma grande lacuna em suas formações, tanto no que se refere aos conteúdos disciplinares como em relação a uma vivência cultural. Muitos estudantes permanecem no Práxis por dois ou três anos para somente então serem aprovados nos exames e ingressarem no ensino superior. No entanto, mesmo os jovens pertencentes às classes médias e às elites, oriundos de escolas públicas e particulares, frequentam em sua maioria os cursos pré-vestibulares, o que, de acordo com Whitaker (2010), "atesta o fracasso do sistema em preparar seus jovens para o vestibular" (p. 290).

Paula, mesmo após as tentativas malsucedidas de ingressar no ensino superior, não desistiu do seu sonho de estudar em uma universidade. Quando conseguiu trabalhar como empregada doméstica e teve sua carteira assinada, decidiu que era hora de tentar novamente. Resolveu, então, cursar o Pré-Universitário Popular Práxis, mas a seleção de 2008 estava encerrada. No outro ano, ingressou em outro pré-vestibular popular. Em 2010, Paula conseguiu participar do processo seletivo realizado pelo Práxis e ingressou no curso que desde o início desejava fazer, por ser um pré-vestibular vinculado à UFF.

Sobre seu início nos cursos pré-vestibulares, Paula disse que sentiu uma dificuldade enorme para compreender os conteúdos, especialmente das disciplinas que compõem a área de exatas. No entanto, para superar essa dificuldade, relatou que pedia insistentemente a ajuda dos professores e de colegas e estudava muito. Contou que a persistência de alguns 
membros da equipe do Práxis, coordenadores e professores, encantava-a e fazia com que ficasse ainda mais firme em seu propósito de continuar a estudar. Disse que conversava com todos e que encontrou no grupo uma verdadeira família. Indaguei a Paula o que achou das atividades culturais oferecidas aos alunos pelo Práxis. Ela disse que eram maravilhosas, pois pôde usufruir de exposições realizadas no Centro Cultural do Banco do Brasil, situado no Rio de Janeiro, local que, segundo ela, passou a ser a casa dos alunos, pois fizeram muitas visitas a esse centro, além de outras a museus, a um quilombo etc.

Em 2013, Paula conseguiu finalmente ser aprovada para cursar História na UERJ, curso que decidiu fazer depois de pensar bastante sobre o assunto e conversar com professores. De acordo com ela, utilizou a cota racial somente porque um colega do Práxis insistiu para que o fizesse. As informações sobre o sistema de cotas foram dadas a ela pelas equipes dos pré-vestibulares populares que cursou.

Paula relatou a imensa alegria sentida ao receber de um colega a notícia sobre sua aprovação e o alívio que experimentou. Ela afirmou, categoricamente, que sem a ajuda dos cursos pré-vestibulares não teria sido possível o acesso ao ensino superior, nem mesmo com o auxílio da cota racial. E disse que, além de conseguir superar as lacunas em sua formação escolar, os professores dos pré-vestibulares que frequentou deram explicações sobre o sistema de cotas e como utilizá-lo.

Carlos, desde criança, quando ainda estudava no Ciep, escolheu o curso universitário que iria fazer: desejava cursar Direito e ser advogado. O entrevistado relatou que, quando falava sobre seu desejo para as pessoas, elas o olhavam com pena, por ele ser negro, pobre e estudante de escola pública. Disse que em momentos de desânimo se lembrava de sua mãe incentivando-o a enfrentar as situações difíceis da vida e a continuar lutando pelo seu sonho de estudar Direito. Segundo narrou, ela sempre dizia: "Carlos, se alguém conseguiu fazer isso, você também pode fazer".

Perguntei ao participante como surgiu seu desejo de cursar Direito, pois em sua família materna não havia advogados, seus tios eram analfabetos e em seu círculo de amizades também não havia pessoas que exerciam tal profissão. Além disso, suas condições objetivas de vida representavam um grande obstáculo para que até mesmo sonhasse com essa profissão. No entanto, seu pertencimento social e racial não o impediram de desejar formar-se em Direito. Carlos afirmou que desde criança procurava informações sobre as diversas profissões e um dia viu na televisão ou em uma revista - ele não soube informar com precisão - um senhor muito elegante usando terno e gravata, o qual era um promotor de justiça. Penso que a imagem desse senhor representou para Carlos de forma simbólica seu desejo de obter ascensão social por meio do estudo.

Carlos ingressou em um pré-vestibular popular em um período economicamente bastante difícil de sua vida. Solicitei a ele que relatasse sobre as dificuldades enfrentadas durante o tempo passado nesse curso e ele disse que percebeu as várias lacunas de seus conhecimentos, especialmente em Química.

No outro ano, Carlos começou a cursar o Pré-Universitário Popular Práxis, no qual permaneceu por um ano e meio, aproximadamente. No final 
do ano, prestou o vestibular da UERJ para Direito, foi aprovado, mas não logrou uma classificação correspondente ao número de vagas existente.

Com relação ao tempo passado no Práxis, Carlos comentou que foi uma época de muito estudo, mas que os professores e coordenadores não realizavam passeios culturais com os alunos. Relatou, ainda, que só tinha ido ao cinema uma vez, aos 11 anos, com sua mãe, e ficara encantado. Perguntei se havia feito passeios culturais nas escolas em que estudou e ele respondeu que essas instituições não os promoveram. Carlos ressaltou que o tempo em que estudou no Práxis foi fundamental, pois ele apresentava uma grande lacuna em sua formação escolar e os professores desse curso o ajudaram a preenchê-la.

O participante obteve aprovação em três universidades: Universidade Federal do Rio de Janeiro (UFRJ), UERJ e UFF. Nas duas primeiras, foi aprovado para cursar Direito e, na UFF, para cursar Engenharia de Telecomunicações. Optou por estudar Direito na UERJ, por ter informações positivas sobre essa universidade. Disse que tentou utilizar o sistema de cotas, mas não conseguiu porque faltaram os documentos de sua mãe para a comprovação da renda da família. Quando entrevistei Carlos em 2013, ele havia se formado em Direito há um ano e conseguido aprovação no exame da Ordem dos Advogados do Brasil (OAB), e exercia a profissão de advogado.

\section{Considerações finais}

As histórias narradas por Paula e Carlos sobre suas trajetórias escolares e pessoais evidenciam os inúmeros obstáculos enfrentados pelos indivíduos oriundos das classes populares para estudarem e terem acesso ao ensino superior. Os percursos escolares costumam ser extremamente acidentados e os indivíduos tendem a adotar estratégias para prosseguir nos estudos. Havia nas famílias dos participantes uma regularidade em relação a atividades, horários e regras, que compensou, de certa forma, o reduzido capital escolar e econômico que os pais possuíam.

De acordo com Lahire (2004), os indivíduos não são redutíveis a sua classe social, sexo ou nível cultural. Portanto, é necessário analisar esses pertencimentos levando em consideração o conjunto de relações que tais indivíduos estabelecem ao longo de suas vidas. Paula, por exemplo, relatou que adquiriu o gosto pela leitura, tão importante para uma escolarização de sucesso, quando entrou para a Igreja Batista e passou a estudar intensamente a bíblia. Carlos, que possuía uma grande timidez que o impedia de falar em público, resolveu tal questão, que seria um empecilho para a tão sonhada profissão de advogado, quando passou a trabalhar em uma loja.

Houve um grande esforço pessoal dos entrevistados que deve ser também considerado para a compreensão sobre a longevidade escolar que obtiveram. Além disso, narraram o encontro ocorrido, ao longo de suas trajetórias escolares, com alguns bons professores, que exerceram sobre eles uma influência positiva. E preciso mencionar, também, a grande iniciativa demonstrada por Paula e Carlos para superarem os obstáculos que surgiram ao longo de suas trajetórias escolares. 
Ainda que os entrevistados tenham encontrado bons professores nas escolas em que estudaram, essas instituições não se preocupavam em proporcionar a seus alunos uma rica vivência cultural. Para os indivíduos pertencentes às classes médias e altas, esse tipo de problema costuma ser solucionado com maior facilidade, pois se as escolas frequentadas por eles falham nessa direção, os pais rapidamente suprem essa deficiência, mas o mesmo tende a não ocorrer com os indivíduos das classes populares. Além disso, Carlos relatou as lacunas deixadas pelas escolas em que estudou no que se refere ao conhecimento de conteúdos disciplinares, como em Química. Professores que faltavam às aulas e escolas em processo de decadência foram alguns dos problemas vivenciados pelo entrevistado ao longo de sua escolarização.

O Pré-Universitário Popular Práxis e outros pré-vestibulares frequentados por Paula e Carlos mostraram-se fundamentais para que eles tivessem acesso ao ensino superior. Foi por meio desses cursos que puderam superar em parte as inúmeras lacunas existentes em suas formações escolares e, no caso de Paula, obter informações valiosas para entender o sistema de cotas e poder utilizá-lo. No entanto, tais cursos tão importantes para que indivíduos dos meios populares possam ser aprovados em exames vestibulares promovidos por instituições superiores de ensino e no Enem enfrentam sérios problemas para exercerem suas atividades. Existe também no Práxis, e em outros pré-vestibulares populares, uma grande evasão de alunos durante o ano, ocasionada por diversos motivos, como dificuldade de conciliar trabalho e estudo, baixa autoestima e falta de dinheiro para pagar as passagens de ônibus e frequentar o curso, problemas que poderiam ser mais facilmente enfrentados se houvesse um maior apoio institucional.

É preciso ressaltar a importância dos passeios culturais que a equipe do Práxis realiza com seus alunos. Ao permitir que os estudantes conheçam museus e assistam a filmes e peças teatrais, a equipe do Práxis os ajuda a adquirirem um certo capital cultural fundamental, entre outras coisas, para um destino escolar de sucesso. As aulas temáticas ministradas pelos professores do Práxis são também relevantes para que os estudantes tenham conhecimento de questões e temas que os possibilitem desenvolver o espírito crítico e tendem a despertar o desejo de lutar por um mundo mais igualitário. Esse tipo de aula constitui um dos diferenciais dos cursos pré-vestibulares populares em relação a outros pré-vestibulares existentes.

Para que possamos viver em uma sociedade mais democrática e justa, pensamos que o caminho percorrido pelos indivíduos pertencentes às classes populares precisa ser mais bem conhecido, a fim de que possamos compreender as particularidades desses sujeitos e as possibilidades de intervenção por parte de professores, instituições escolares e Estado. Os cursos pré-vestibulares populares vêm cumprindo um importante papel ao possibilitar que indivíduos das classes desfavorecidas socialmente consigam ter acesso ao ensino superior. No entanto, tal contribuição prestada por esses cursos ainda permanece bastante desconhecida por grande parte da sociedade, e os estudos sobre eles ainda são insuficientes para os compreendermos. Tal compreensão nos tornará mais conscientes dos limites e dos desafios referentes ao acesso das classes populares ao ensino superior e às possibilidades de intervenção nesse campo. 


\section{Referências bibliográficas}

BOURDIEU, P. A economia das trocas simbólicas. São Paulo: Perspectiva, 2003.

BOURDIEU, P. Escritos de educação. In: NOGUEIRA, M. A.; CATANI, A. (Org). A escola conservadora: as desigualdades frente à escola e à cultura. Petrópolis: Vozes, 1998. p. 39-64.

BRASIL. Lei $n^{\circ} 12.711$, de 29 de agosto de 2012. Dispõe sobre o ingresso nas universidades federais e nas instituições federais de ensino técnico de nível médio e dá outras providências. Diário Oficial da União, Brasília, DF, 30 ago. 2012. Seção 1, p. 1.

CARVALHO, J. C. B. Os cursos pré-vestibulares comunitários e seus condicionantes pedagógicos. Cadernos de Pesquisa, São Paulo, v. 36, n. 128 , p. 299-326, maio/ago. 2006.

DIAS, R. L. C. Repercussões da formação em nível superior nas práticas pessoais e profissionais de professores das camadas populares. $230 \mathrm{f}$. Tese (Doutorado em Educação) - Faculdade de Educação, Universidade Federal de Minas Gerais, Belo Horizonte, 2010.

LAHIRE, B. Retratos sociológicos: disposições e variações individuais. Porto Alegre: Artmed, 2004.

LAHIRE, B. Sucesso escolar em meios populares: as razões do improvável. São Paulo: Ática, 1997.

LAURENS, J. P. I sur 500: la reussite scolaire em milieu populaire.

Toulouse: Presses Universitaires du Mirail, 1992.

MENEZES, E. T. de. CIEPs (Centros Integrados de Educação Pública). São Paulo: Midiamix, 2001. Disponível em: <http://www.educabrasil. com.br/cieps-centros-integrados-de-educacao-publica/ > . Acesso em: 28 mar. 2016.

NASCIMENTO, A. Do direito à universidade à universalização do direito: o movimento dos cursos pré-vestibulares populares e as políticas de ação afirmativa. Rio de Janeiro: Litteris, 2012.

NOGUEIRA, M. A.; NOGUEIRA, C. M. M. Bourdieu e a educação. Belo Horizonte: Autêntica, 2004.

OLIVEIRA, V. M.; MARTINS, M. F.; VASCONCELOS, A. C. F. Entrevistas "em profundidade" na pesquisa qualitativa em administração: pistas teóricas e metodológicas. In: SIMPÓSIO DE ADMINISTRAÇÃO DA 
PRODUÇÃO, LOGISTICA E OPERAÇÕES INTERNACIONAIS - SIMPOI, 15., 2012, São Paulo. Anais... São Paulo, 2012. Disponível em: <www. simpoi.fgvsp.br/arquivo/2012/artigos/E2012_T00259_PCN02976.pdf > . Acesso em: 29 jan. 2017.

OLIVEN, A. C. Ações afirmativas, relações raciais e política de cotas nas universidades: uma comparação entre os Estados Unidos e o Brasil. Educação, Porto Alegre, v. 30, n. 1, p. 29-51, jan./abr. 2007.

PORTES, E. A. Trajetórias escolares e vida acadêmica do estudante pobre da UFMG. 2001. 267 f. Tese (Doutorado em Educação) - Faculdade de Educação, Universidade Federal de Minas Gerais, Belo Horizonte, 2001.

PORTES, E. A. As propostas de políticas/ações afirmativas das universidades públicas e as políticas/ações de permanência nos ordenamentos legais. Revista Brasileira de Estudos Pedagógicos, Brasília, DF, v. 92, n. 232, p. 516-541, set./dez. 2011.

ROMANELLI, O. O. História da educação no Brasil. Petrópolis: Vozes, 2007.

SILVA, J. S. Por que uns e não outros: caminhada de jovens pobres para a universidade. Rio de Janeiro: 7Letras, 2011.

VARGAS, H. M. Ensino superior em expansão: mudanças no perfil socioeconômico do alunado?. Boletim SOCED, Rio de Janeiro, v. 5, p. 13-17, 2008.

VIANA, M. J. B. Longevidade escolar em famílias populares: algumas condições de possibilidade. Goiânia: Ed. UCG, 2007.

WHITAKER, D. C. A. Da "invenção" do vestibular aos cursinhos populares: um desafio para a orientação profissional. Revista Brasileira de Orientação Profissional, Ribeirão Preto, v. 11, n. 2, p. 289-297, jul./dez. 2010.

ZAGO, N. Quando os dados contrariam as previsões estatísticas: os casos de êxito escolar nas camadas socialmente desfavorecidas. Paideia, Ribeirão Preto, v. 10, n. 8, p. 70-80, 2000.

ZAGO, N. Cursos pré-vestibulares populares: limites e perspectivas. Perspectiva, Florianópolis, v. 26, n. 1, p. 149-174, jan./jun. 2008.

Recebido em 26 de abril de 2016.

Aprovado em 30 de novembro de 2016. 